\title{
Viral Infection of Vascular Endothelial Cells Alters Production of Colony-stimulating Activity
}

Stanton L. Gerson, Harvey M. Friedman, and Douglas B. Cines

Division of Hematology-Oncology, University Hospitals of Cleveland, Cleveland, Ohio 44106; and the Divisions of Infectious Diseases and Hematology-Oncology, Hospital of the University of Pennsylvania, Philadelphia, Pennsylvania 19104

\begin{abstract}
Viral infections in humans are frequently associated with granulocytopenia and/or granulocytosis. Such changes in myelopoiesis could result from infection of the granulocyte-macrophage colony-forming cell (CFC-GM) or changes in the production of colony-stimulating activity (CSA). Endothelial cells are a known source of CSA and may be transiently or persistently infected during a number of viral infections, including infection with herpes simplex virus type I (HSV-I) and measles virus. Therefore, we examined the effect of endothelial cell infection with these two viruses on the production of CSA.

Uninfected passaged endothelial cells produce CSA when stimulated by the continual presence of a factor present in medium conditioned by peripheral blood monocytes (MCM). Within $4 \mathrm{~h}$ of infection with HSV-I, endothelial cells no longer produced CSA in response to MCM. In contrast, measles virus infection induced CSA production by passaged endothelial cells even in the absence of MCM. Measles virus-induced CSA production was maximal at $24 \mathrm{~h}$ and required the presence of live virus within the endothelial cells.

The effects of HSV-I and measles virus on CSA production were not dependent on alterations in the production of $\alpha$ - or $\boldsymbol{\gamma}$-interferon by the infected endothelial cells. Infection with HSVI did not stimulate endothelial cells to release any detectable interferon. In contrast, the supernatants of the measles-infected cells contained only $\beta$-interferon, a known inhibitor of CFC-GM development.

These studies suggest that CSA production by endothelial cells is directly altered by infection with HSV-I and measles virus. An alteration in CSA production might contribute to changes in myelopoiesis that frequently accompany viral infection in humans.
\end{abstract}

\section{Introduction}

Growth of myeloid progenitors within the bone marrow is believed to depend on a series of glycoproteins collectively known as colony-stimulating factors (1). A variety of normal cells and malignant cell lines grown in tissue culture (2-5) have been shown to secrete proteins that have colony-stimulating activity (CSA). ${ }^{1}$ The ability of CSA to promote myelopoiesis in vitro

Correspondence should be addressed to Dr. Cines, Cancer Center, 7 Silverstein, Hospital of the University of Pennsylvania, Philadelphia, PA 19104.

Received for publication 12 February 1985.

1. Abbreviations used in this paper: CFC-GM, granulocyte-macrophage colony-forming cell; CMV, cytomegalovirus; CSA, colony-stimulating

J. Clin. Invest.

(C) The American Society for Clinical Investigation, Inc.

0021-9738/85/10/1382/09 \$1.00

Volume 76, October 1985, 1382-1390 can be inhibited by the addition of acidic isoferritins, lactoferrin, prostaglandin $E_{1}$, and certain types of interferon (6-9). However, far less is known about the relative importance of the actual level of CSA or the relative roles of each of these inhibitors of colony formation in clinical disorders of granulopoiesis.

For example, viral infections are frequently associated with the development of granulocytosis and/or granulocytopenia (1013), but the mechanisms by which these occur have received little study. Lymphocytes with the T helper phenotype, which are the most prevalent subset of $T$ cells in healthy normal individuals, have been shown to be an important source of CSA $(3,14)$. Infection with Epstein-Barr virus (EBV) and cytomegalovirus (CMV) may be accompanied by the development of neutropenia (15-17). Both of these viruses induce the proliferation of T suppressor cells (15-17), which may inhibit the growth of granulocyte-macrophage colony-forming cells (CFC-GM) (18) and may produce less CSA than the normal T helper cells. Either event might lead to the development of neutropenia.

Other mechanisms by which neutropenia might develop are also possible. Several viruses, such as parvoviruses, are capable of replicating within marrow progenitor cells $(11,19)$. The responsiveness of bone marrow cells to either CSA or its inhibitors could be directly affected by the presence of virus. Retroviruses and other viruses are also capable of directly modifying the synthesis or release of CSA by certain infected cells (20).

We have previously shown that several common human viruses are capable of infecting and replicating within human endothelial cells, a known source of CSA (21-23). We therefore studied whether infection of endothelial cells with certain of these viruses would alter their production of CSA.

\section{Methods}

\section{Endothelial cell culture}

Primary cultures of human umbilical venous endothelial cells were established as previously described $(23-28)$ and passaged by a 3-5-min exposure to $1 \%$ trypsin/EDTA (Gibco Laboratories, Grand Island, NY) (26). Over $95 \%$ of the cells in the monolayer were Factor VIII antigen positive $(23,26)$. Nonspecific esterase (NSE), compatible with the presence of monocytes, was found on $<5 \%$ of the cells in primary cultures and was not detected in subsequent passages.

\section{Viral infection of endothelial cells}

$24 \mathrm{~h}$ after passage, endothelial cells were infected with either herpes simplex virus type I (HSV-I) or the Edmonston vaccine strain of measles virus as previously described (22). Briefly, the medium was removed from the monolayers and the cells were incubated with HSV-I, at a

activity; EBV, Epstein-Barr virus; Endo-CM, endothelial cell-conditioned medium; HSV-I, herpes simplex virus type I; MCM, monocyte-conditioned medium; MRA, monocyte-derived recruiting activity; NSE, nonspecific esterase; PDB, phorbol 12,13-dibutyrate; PHA, phytohemagglutinin; PHA-LCM, PHA lymphocyte-conditioned medium. 
multiplicity of input (MOI) of one infectious virus per cell $\left(1.0 \times 10^{5}\right.$ tissue culture infectious doses of virus/well), or with measles virus at an $\mathrm{MOI}$ of 0.3 . The virus was allowed to adsorb to the cell for $1 \mathrm{~h}$ at $37^{\circ} \mathrm{C}$, the monolayer was washed, and control or modified medium containing $10 \%$ fetal calf serum (FCS) was added. In each experiment, replicate cultures were sham-infected with the vehicle or medium in which the virus was prepared.

To determine whether measles virus must replicate within the endothelial cells for CSA to be produced, experiments were performed in parallel with endothelial cells exposed to UV-inactivated virus, which we prepared as previously described (21). This exposure of measles virus to UV light reduced the titer of infectious virus from $3 \times 10^{5}$ virions/ $\mathrm{ml}$ to 0 .

Since the amount of CSA in our experiments was determined by the growth of human bone marrow cells (see below), the presence of live virus in the supernatants of measles or HSV-I-infected endothelial cells could alter the amount of CSA we subsequently detected. Similarly, the presence of residual live virus could affect the measurement of interferon activity (see below). Therefore, any potential live virus was removed from replicate culture supernatants in these experiments by two methods. First, live virus potentially present in the culture supernatants was inactivated with UV light as above. Then, intact (inactivated) viral particles were removed by ultracentrifugation at $100,000 \mathrm{~g}$ for $18 \mathrm{~h}$ at $4^{\circ} \mathrm{C}$ before their addition to the human bone marrow cells (for CSA determinations) or fibroblasts (for determination of interferon) (see below). All titrations of live measles virus and HSV-I were performed in MRC-5 strain human embryonic lung fibroblasts (22).

\section{Preparation of conditioned medium}

Monocyte-conditioned medium (MCM). MCM was prepared by a modification of the method of Bagby et al. $(29,30)$ as previously described (31). Briefly, a low density mononuclear cell population was prepared from whole blood by Ficoll-Hypaque (Pharmacia Fine Chemicals, Piscataway, $\mathrm{NJ}$ ) gradient centrifugation and resuspended in RPMI culture medium (Gibco Laboratories) at $2 \times 10^{6}$ cells $/ \mathrm{ml}$. The cells were allowed to adhere to FCS-pretreated 75- $\mathrm{cm}^{2}$ tissue culture flasks (Costar Data Packaging Corp., Cambridge, MA) for 90-120 min (30 ml/flask) (7). The nonadherent cells were removed by aspiration and the adherent monolayer was washed twice with RPMI 1640 culture medium (Gibco). Over $90 \%$ of the adherent cells showed positive staining for NSE and were therefore considered to be monocytes (31). 1-3 $\times 10^{5}$ cells/ml were then placed in $20 \mathrm{ml}$ of RPMI 1640 containing $10 \% \mathrm{FCS}$ for $5 \mathrm{~d}$ at $37^{\circ} \mathrm{C}$ in an atmosphere of $5 \% \mathrm{CO}_{2}$, at which time the culture medium was centrifuged at $500 \mathrm{~g}$ for $10 \mathrm{~min}$ and filtered through a Nalgene $0.45-\mu \mathrm{m}$ filter (Sybron Corp., Rochester, NY). This MCM was stored at either $4^{\circ} \mathrm{C}$ for up to $1 \mathrm{mo}$ or at $-20^{\circ} \mathrm{C}$ for up to 2 mo before use as a supplement for the endothelial cell cultures. We found that preparations of MCM we had stored at $4^{\circ} \mathrm{C}$ retained a greater ability to induce CSA than samples that had been frozen and thawed.

Endothelial cell-conditioned medium (Endo-CM). Supernatants from endothelial cell cultures, which we have designated Endo-CM, were prepared by centrifuging the cell culture at $500 \mathrm{~g}$ for $10 \mathrm{~min}$. Endo-CM was stored at $-20^{\circ} \mathrm{C}$ for up to 6 mo without loss of CSA. Endo-CM was harvested from the endothelial cells prepared using several different culture conditions: (a) primary cultures of endothelial cells without additional stimulation were studied from the time the cells were initially placed in culture (time zero) and daily thereafter for $1 \mathrm{wk} ;(b)$ endothelial cell monolayers were prepared after a single passage and similarly studied over the first week without additional stimulation; $(c)$ passaged endothelial cells were incubated with 0 or $25 \%$ MCM for $0-8 \mathrm{~d}$ before removing the Endo-CM; $(d)$ passaged endothelial cells were infected with live or UVinactivated measles virus or HSV-I, or were sham-infected as detailed above. One half of the endothelial cell cultures were then incubated in complete medium alone while the other half were incubated in complete medium supplemented with $25 \% \mathrm{MCM}$.

We also performed a series of experiments to determine whether the response of the endothelium to MCM was specific or whether endothelial cells released CSA when a variety of potentially stimulating materials was added. In certain experiments, primary or passaged endothelial cell cultures were incubated for periods from $2 \mathrm{~h}$ to $8 \mathrm{~d}$ with complete medium supplemented with either 0.1-1\% phytohemagglutinin (PHA) (HA-15; Burroughs Wellcome \& Co., Greenville, NC) or $10^{-9}-10^{-7} \mathrm{M}$ phorbol 12,13-dibutyrate (PDB) (LC Services Corp., Woburn, MA) prepared as previously described (31). To assess whether protein synthesis was required for the expression of CSA activity, cultures of passaged endothelial cells were preincubated with $0.1-10 \mathrm{mg} / \mathrm{ml}$ cycloheximide (Sigma Chemical Co., St. Louis, MO) for 10-60 min before the addition of MCM. Replicate cultures of endothelial cells incubated with complete media alone were initiated for each condition.

To assess cumulative CSA release, conditioned medium was harvested from replicate cultures at sequential time points. To assess CSA release between various time points, conditioned medium was harvested from the same wells at 1-3-d intervals, and the endothelial cell cultures were refed with fresh culture medium. Unless otherwise stated, the formulation of each replacement culture medium was the same as the initial medium throughout the experiment.

\section{Role of interferon}

We also determined whether the virally infected endothelial cells or cells stimulated with MCM secreted $\alpha$-, $\beta$-, or $\gamma$-interferon into the EndoCM. The total amount of interferon in the endothelial cell cultures was determined by assaying the extent of inhibition of the cytopathic effect of vesicular stomatitis virus on both bovine (EbTr strain) and human (Detroit 539 strain) fibroblasts, by established techniques (kindly performed by Dr. Bice Perussia, Wistar Institute, Philadelphia, PA) (32). Antiviral units are expressed as the reciprocal of the dilution inhibiting $50 \%$ of the cytopathic effect and are equivalent to one reference unit of the National Institutes of Health (NIH) human $(\alpha, \gamma)$ reference interferon (IFN G-023-901-527).

The molecular species of interferon synthesized by the endothelial cells was then determined. Each sample containing interferon activity was incubated with an excess of a polyclonal anti- $\alpha$-interferon or a polyclonal anti- $\beta$-interferon antibody $\left(10^{5}\right.$ neutralizing $\left.U / \mathrm{ml}\right)$ (Interferon Sciences, ICN Pharmaceuticals, Inc., Irvine, CA) or with a murine monoclonal anti- $\gamma$-interferon antibody (provided by Drs. Bice Perussia and Giorgio Trinchieri, Wistar Institute, Philadelphia, PA, and containing $3.3 \times 10^{4}$ neutralizing $\mathrm{U} / \mathrm{ml}$ ) before addition to the fibroblast monolayer. Residual interferon activity was then determined at 18 and $48 \mathrm{~h}$. The amount of $\gamma$-interferon secreted into the endothelial cell supernatants was also determined by radioimmunoassay (kindly performed by Dr. Trinchieri). Briefly, a monoclonal anti- $\gamma$-interferon antibody (33) was linked to cyanogen bromide-activated Sepharose 4B; the antibody-coated beads were then incubated with purified NIH $\gamma$-interferon or the endothelial cell supernatants for $3 \mathrm{~h}$ at $22^{\circ} \mathrm{C}$ and $1 \mathrm{~h}$ at $4^{\circ} \mathrm{C}$. The beads were then washed and incubated with a second ${ }^{125} \mathrm{I}$-labeled murine IgG anti- $\gamma$-interferon antibody. After three additional washes, the beads were counted for bound radioactivity in a gamma scintillation counter. Purified $\mathrm{NIH} \gamma$-interferon $(5,000 \mathrm{U})$ was used as the positive control in the experiments; conditioned medium from two PHA (0.3\%) -stimulated normal human mononuclear cell preparations contained a mean of 12,600 $\mathrm{U}$ of activity.

Experiments were also performed to determine whether small amounts of interferon, which were below our ability to detect or which were active within the cell, could play a role in CSA production. Endothelial cells were preincubated with either partially purified $\alpha$-interferon (Leucoferon; Biotechnologies, Inc., Hartford, CT) (1-1,000 U/10 $0^{5}$ cells), identical concentrations of recombinant $\gamma$-interferon (Genentech Inc., San Francisco, CA), or $\gamma$-interferon from stimulated human lymphocytes (Ventrex Laboratories, Portland, MA) in the presence or absence of MCM for $72 \mathrm{~h}$. The cells were then washed and incubated with media containing MCM, MCM plus interferon, or control media for an additional $72 \mathrm{~h}$ before assay.

\section{CFC-GM assay}

The quantity of CSA present in conditioned culture medium (MCM and Endo-CM) was established using a bioassay of CFC-GM as previously 
described (31). Briefly, mononuclear cells were isolated from human bone marrow by Ficoll-Hypaque density gradient centrifugation and allowed to adhere to culture flasks that had been preincubated overnight in normal human serum, for $1 \mathrm{~h}$ at $37^{\circ} \mathrm{C}$ in $10 \% \mathrm{CO}_{2}$. The nonadherent cells were then removed and used to measure CSA in single-layer agar cultures by a modification of the method of Metcalf et al. (5) as previously described $(31,34)$. To perform this assay, marrow cells at $2 \times 10^{6}$ cells/ $\mathrm{ml}$ were diluted 1:20 with an equal mixture of double-strength supplemented Dulbecco's modified Eagle's medium and 0.6\% Bacto agar (Difco Laboratories Inc., Detroit, MI) maintained between 37 and $40^{\circ} \mathrm{C}$. Each source of conditioned medium was placed in a culture dish at $10 \%$ final volume. The mixture of nonadherent bone marrow cells in agar was added and allowed to cool to a gel at $22^{\circ} \mathrm{C}$ for $20 \mathrm{~min}$ before incubation for $14 \mathrm{~d}$ at $37^{\circ} \mathrm{C}$ in a fully humidified incubator in an atmosphere of $10 \% \mathrm{CO}_{2}$. Duplicate or triplicate agar cultures were counted at a magnification of $\mathbf{4 0}$ (American Optical Corp., Buffalo, NY) to determine the number of clusters (10-49 cells) and colonies ( $>50$ cells) that developed. Results are presented as the mean \pm SEM for multiple experiments, using the average combined number of clusters and colonies per $10^{5}$ low density nonadherent marrow cells from each experiment. This mean is referred to as colonies. The standard deviation of triplicate samples was $<10 \%$ of the mean value in an individual experiment. Conditioned media from PHA-stimulated leukocytes (PHA-LCM) were prepared as previously described $(31,34)$ and used as a known source of CSA.

In certain experiments, the colony cell type was delineated by evaluating each colony for the presence of NSE, a monocyte marker, and chloroacetate esterase, a granulocyte marker (31). Colonies in which $>90 \%$ of the cells were of one esterase type were scored as staining for that cell type; otherwise they were scored as mixed.

\section{Preparation of endothelial cell cytosol}

We wanted to know whether the presence of CSA in the endothelial cell supernatants reflected only ongoing synthesis or whether additional CSA was stored within the cell and released after cell lysis. Therefore, we determined the amount of CSA that could be released from endothelial cell cytoplasm after mechanical disruption. To perform this experiment, we prepared endothelial cell cytosol from $\sim 8 \times 10^{6}$ cells per sample. Stimulated, infected, or control cultures of endothelial cells were washed and resuspended in Medium 199. The protease inhibitors phenylmethylsulfonyl fluoride $(17.4 \mathrm{mg} / \mathrm{ml})$, L-glutamyl-L-tyrosine $(44.4 \mathrm{mg} / \mathrm{ml}$ in ethanol), and benzamidine hydrochloride $(1.52 \mathrm{mg} / \mathrm{ml})$ were added. The intact cells were fractured by nitrogen cavitation by exposure to 1,200 1,500 psi for 15 min (Parr Instrument Co., Moline, IL). Large membrane pellets were removed by centrifugation at $10,000 \mathrm{~g}$ for $10 \mathrm{~min}$ (model L5-50; Beckman Instruments, Inc., Fullerton, CA) The supernatants were then spun at $100,000 \mathrm{~g}$ for $30 \mathrm{~min}$ and assayed at a $10 \%$ final volume for CSA.

\section{Results}

\section{CSA release by primary cultures of endothelial cells}

We first determined whether primary cultures of uninfected and unstimulated human umbilical venous endothelial cells released detectable CSA. We found that conditioned medium harvested from primary endothelial cell cultures at $48 \mathrm{~h}$ contained large amounts of CSA (Fig. 1). However, when the cells were incubated for an additional 2-5 d, progressively less CSA was released into the medium, and after the fourth day of culture, little additional CSA was released. A number of agents were then added to day 4 cultures in an attempt to reinduce CSA release. Addition of $0.1-1 \%$ PHA or $10^{-9}-10^{-7} \mathrm{M}$ PDB did not result in significant CSA release by primary cultures between days 4 and 7 .

CSA release by passaged endothelial cells: effect of MCM

Primary cultures of endothelial cells capable of producing CSA were then subcultured. 3-7 d after passage, their supernatants

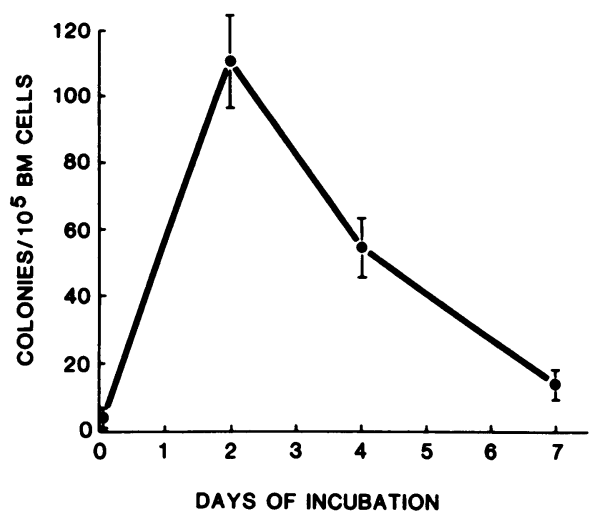

Figure 1. Cumulative production of CSA by primary cultures of endothelial cells. Endothelial cell monolayers were prepared from umbilical cords by collagenase digestion and placed in culture for 1-7 d. Conditioned medium from these cells was used to stimulate colony formation (CFC-GM) from normal human bone marrow (BM) cells. The data shown represent the mean \pm SEM of nine experiments.

were assayed for CSA activity. In contrast to primary cultures, unstimulated endothelial cells after a single passage no longer released detectable CSA at day 3 or day 7 after subculture (Fig. 2). Since unstimulated passaged cells did not release CSA, we felt these cultures would be optimal for the further study of endothelial cell stimulation. We first studied the release of CSA by passaged endothelial cells that had been incubated with MCM, a known inducer of CSA first described by Bagby et al. (29). Medium conditioned by peripheral blood monocytes did not itself contain any CSA (Fig. 2). However, passaged endothelial cells cultured in the continual presence of a $25 \%$ concentration of MCM released large amounts of CSA (Fig. 2). The release of CSA could be almost entirely prevented by preincubating the endothelium with cycloheximide $(1 \mu \mathrm{g} / \mathrm{ml})$, which indicates that production and/or release of CSA may require active protein synthesis. This inhibition was completely reversible by washing and reexposing the cells to MCM in the absence of cycloheximide. Furthermore, release of CSA by passaged endothelial cells

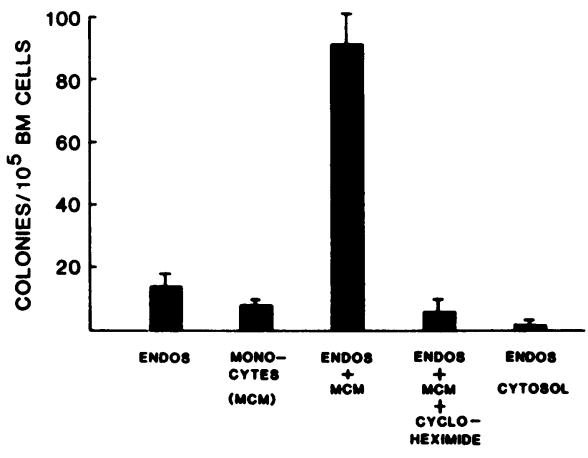

SOURCE OF CONDITIONED MEDIUM

Figure 2. Production of CSA by passaged endothelial cells. Confluent monolayers of passaged endothelial cells were incubated for $72 \mathrm{~h}$ in the presence or absence of MCM and assayed for release of CSA. Monocyte supernatants alone (MCM) contained no CSA. Endothelial cells preincubated with cycloheximide $(1 \mu \mathrm{g} / \mathrm{ml})$ no longer responded to MCM. Cytosol from MCM-stimulated endothelial cells prepared by nitrogen cavitation contained no detectable CSA. The results are expressed as the mean \pm SEM of three to nine experiments for each condition. BM, bone marrow. 
required the continual presence of MCM (Fig. 3). Maximal production of CSA occurred 24-48 h after addition of MCM (Fig. 4). When endothelial cells were first incubated with MCM for $72 \mathrm{~h}$, washed, and reincubated for three sequential 24-h periods in control medium lacking MCM, we found a gradual reduction in CSA release. By 48-72 $\mathrm{h}$ after the MCM was removed, almost no additional CSA was released (Fig. 3). As we observed with primary cultures, passaged endothelial cells did not secrete CSA after the addition of PDB or PHA. Therefore, the effect of MCM was not due to manipulation of the cell culture itself.

We then sought to determine whether unstimulated or MCM-stimulated endothelial cells stored large amounts of CSA within their cytosol. To perform this experiment, we determined the amount of CSA in the cytosol of unstimulated and MCMstimulated endothelial cells after cell lysis. We found no detectable CSA in either cytosol preparation (Fig. 2). These data suggested to us that MCM induces both the synthesis and prompt release of most CSA produced by endothelial cells, although we cannot exclude the possibility that some CSA remains associated with the internal membrane fraction or that inhibitors of CSA may be present as well. The results further suggested that the presence of CSA in Endo-CM did not reflect nonspecific release of glycoproteins that had accumulated within the cell at an earlier time and that were then released after cell lysis or death.

\section{$C S A$ release by endothelial cells infected with $H S V-I$}

We chose to study endothelial cell production of CSA after infection with two viruses that have differing effects on these cells in vitro. Under the conditions of these experiments, HSV-I produces a rapidly progressive infection of the endothelium, with evidence of cell rounding and detachment by 24-72 h after infection. Therefore, this virus was chosen to determine the effect of cell injury and disruption on CSA release. In contrast, measles infection does not produce early endothelial disruption. Viral replication occurs between 48 and $96 \mathrm{~h}$ after infection, the release of viral particles first being detectable at $72 \mathrm{~h}$. The cells begin to produce syncytia, with the loss of distinct cell contours by day 4 . Infected cells continue to release viral particles for up to $10 \mathrm{~d}$, with only a gradual loss of cell attachment and viability (22).

Passaged endothelial cells were exposed to HSV-I for $1 \mathrm{~h}$, washed, and then incubated with control culture medium or medium supplemented with $25 \%$ MCM to stimulate CSA production. Cultures of endothelial cells that had been sham-infected with fresh media alone and then exposed to MCM showed the expected production of CSA within $24 \mathrm{~h}$ (Fig. 5). In contrast, no CSA was released by HSV-I-infected endothelial cells grown

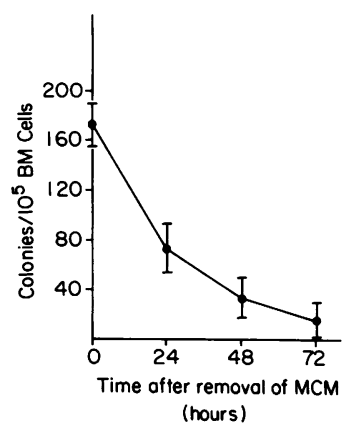

Figure 3. Requirement for the presence of MCM for the production of CSA. Passaged endothelial cells were cultured for $72 \mathrm{~h}$ in conditioned media supplemented with $25 \%$ MCM. At time zero, the endothelial cell culture supernatants were harvested and assayed for CSA. The endothelial cells were washed and reincubated in complete media not supplemented with MCM. Supernatants were harvested at 24-h intervals and assayed for CSA. The mean \pm SEM of 6-11 experiments at each time point is shown. BM, bone marrow.

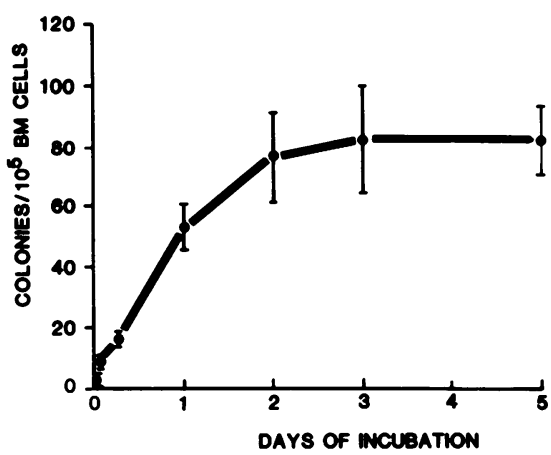

Figure 4. Time course of CSA production by passaged endothelial cells incubated with MCM. Confluent monolayers of passaged endothelial cells were incubated with media supplemented with $25 \% \mathrm{MCM}$. At the indicated time points, conditioned medium was harvested and assayed for CSA. The data shown represent the mean \pm SEM of four experiments. BM, bone marrow.

either in the absence or presence of $25 \%$ MCM for $24 \mathrm{~h}$. Thus, HSV-I abolished the ability of endothelial cells to produce CSA. By $24 \mathrm{~h}$ in culture, complete viral replication of HSV-I can be detected and the endothelial cells show foci of cell swelling and detachment. Therefore, experiments were also performed to determine whether CSA release was inhibited at earlier time points before the production of complete virions, well before any cytopathology was evident. CSA could be detected in the supernatants of uninfected endothelial cells beginning $4 \mathrm{~h}$ after MCM was added. In contrast, no CSA was detected in supernatants of MCM-stimulated endothelial cells infected with HSV-I at $4 \mathrm{~h}$ or at any time point after infection. Two experiments were continued for $8 \mathrm{~d}$ until all cells within the monolayer had become infected and extensive cell detachment and lysis were evident. Conditioned medium from these cultures obtained at multiple time points also contained no CSA. Finally, we determined whether residual intact HSV-I virions might be present in the endothelial cell supernatants and could directly inhibit colony formation in the presence of known amounts of CSA. No active CSA was present in endothelial cell supernatants that had been UV-irradiated and ultracentrifuged before assay; these supernatants contained no infectious virus. We also observed no inhibition of colony formation when supernatants of HSV-I-infected endothelial cells were added to bone marrow cells either

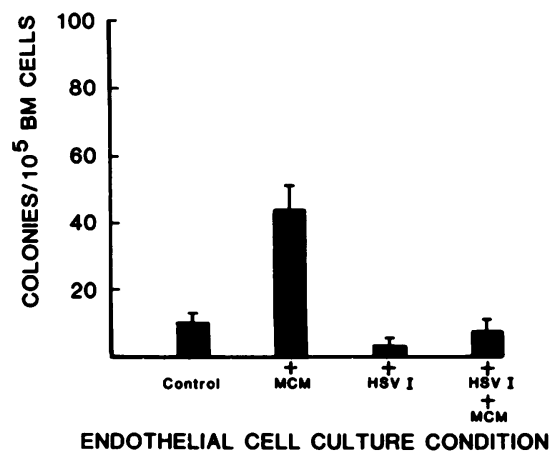

Figure 5. Effect of HSV-I on CSA production by endothelial cells. Passaged endothelial cells grown in control media or media supplemented with MCM were either sham-infected or infected with HSV-I and allowed to incubate for an additional $24 \mathrm{~h}$. Conditioned media were then assayed for CSA. The mean \pm SEM of six experiments is shown. $\mathrm{BM}$, bone marrow. 
before or after stimulation with PHA-LCM compared with cells stimulated with PHA-LCM alone.

\section{CSA release by endothelial cells infected with measles virus}

We performed similar experiments to determine the effect of infection with measles virus on the release of CSA by endothelial cells. Passaged endothelial cells were exposed to measles virus for $1 \mathrm{~h}$ (or were sham-infected), washed, and then incubated for $3 \mathrm{~d}$ in control culture medium or medium containing $25 \% \mathrm{MCM}$. Measles-infected endothelial cells produced CSA in the absence of added MCM (Fig. 6). Measles-infected cells produced additional CSA in the presence of MCM. To determine whether the effect of measles virus on CSA production required the presence of live virus, measles virus was UV-inactivated before infection. UV-inactivated measles, which attaches to the endothelium but does not replicate, did not induce CSA production.

We then determined the time course of CSA production by endothelial cells after measles infection. Measles-infected endothelial cells were kept in culture for $8 \mathrm{~d}$ in control medium or medium containing $25 \% \mathrm{MCM}$. The conditioned medium from the same set of cultures was harvested and replaced with fresh medium at $0,1,2,4,6$, and $8 \mathrm{~d}$ from the onset of infection. Uninfected endothelial cells cultured in the presence of $\mathrm{MCM}$ continued to produce CSA for the entire 8-d period of culture (Fig. 7). In contrast, measles-infected endothelial cells produced their maximal amount of CSA within the first $24 \mathrm{~h}$, a lesser amount of CSA between days 1-3, and no additional CSA thereafter. However, these measles-infected cells retained the capacity to produce CSA in response to MCM for up to $6 \mathrm{~d}$ in culture.

We next asked whether the presence of live measles virus in the endothelial cell supernatants altered the apparent level of CSA we observed, by infecting and directly stimulating target cells within the bone marrow cell assay system. To test this possibility, any live virus potentially present in the endothelial cell supernatants was inactivated with UV light, viral particles were removed by ultracentrifugation, and the Endo-CM was reassayed for CSA activity. No live measles could be detected in these UVinactivated endothelial cell culture supernatants when they were added to a permissive cell line in which viral growth produces visible pathologic changes (22). Nevertheless, the amount of CSA present in the supernatants of measles-infected endothelial cells

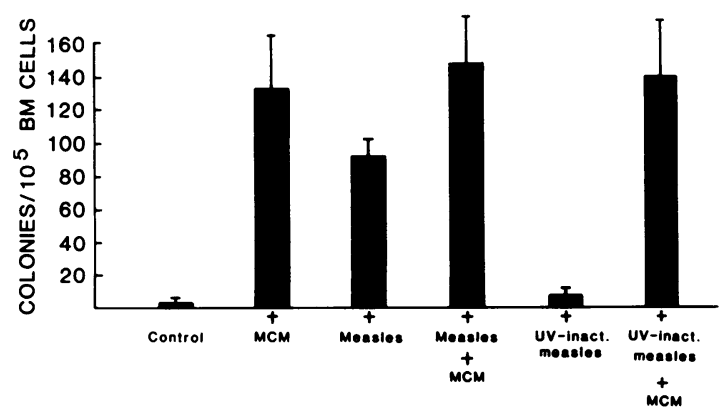

ENDOTHELIAL CELL CULTURE CONDITION

Figure 6. Effect of measles virus on production of CSA by endothelial cells. Passaged endothelial cells grown in either control or MCM-supplemented media were sham-infected, infected with live or UV-inactivated measles virus for $2 \mathrm{~h}$, washed, and allowed to remain in culture for an additional $72 \mathrm{~h}$. Conditioned media were then harvested and assayed for CSA. The mean \pm SEM of four experiments is shown. BM, bone marrow.

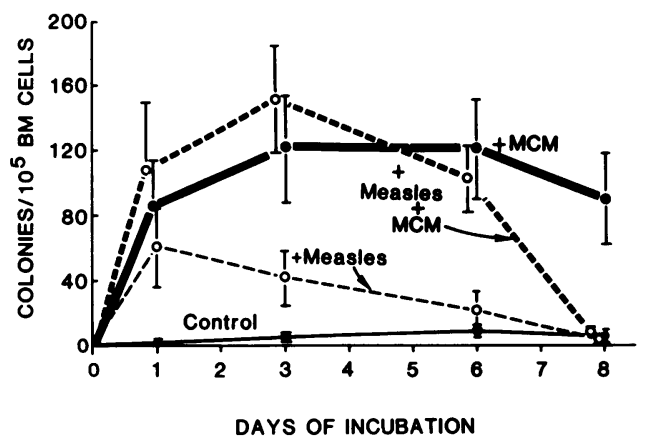

Figure 7. Time course of CSA production by measles-infected endothelial cells. Passaged endothelial cells grown in control or MCM-supplemented media were sham-infected (control) or infected with measles virus at time zero (origin). Conditioned media were then harvested on days $1,3,6$, and 8 from the same wells and assayed for CSA. The mean \pm SEM of eight experiments is shown. BM, bone marrow.

was totally unaffected. Therefore, the biologic measurement of CSA in these supernatants was not influenced by the presence of live measles virus or viral particles.

\section{Role of interferon}

We next investigated whether the production of CSA that we observed in the virally infected endothelial cells was mediated by their production of interferon. This possibility concerned us for two reasons. Endothelial cells in culture might secrete one or more species of interferon. In this case, the absence of CSA in the HSV-I-infected cultures could be due to the induction and release of increased amounts of $\alpha-, \beta$-, or $\gamma$-interferon, known inhibitors of CFC-GM development (9). The presence of CSA in the measles-infected cells could then be due to diminished production of these inhibitors. Alternatively, endothelial cells have been shown to respond to exogenous $\gamma$-interferon by increasing the expression of Dr antigen on the cell surface (35), and might, therefore, be induced to secrete other glycoproteins as well. In this case, the induction of CSA by the measles-infected endothelial cells could be mediated, in part, by the production of one or more interferons having a stimulatory effect on endothelial cells analogous to the effect of MCM.

To test this hypothesis, we used two approaches. First, we directly measured the level of interferon in the endothelial cell supernatants. Second, we measured the amount of CSA in endothelial cell cultures after the addition of $\alpha$ - and $\gamma$-interferon.

We found that neither unstimulated nor MCM-stimulated passaged endothelial cells secreted interferon active on bovine or human fibroblasts (Fig. $8 \mathrm{~A}$ ). In addition, the supernatants of endothelial cells that had been infected with HSV-I for 6, 24, or $48 \mathrm{~h}$ also contained little ( $\leq 2 \mathrm{U}$ ) interferon (Fig. $8 \mathrm{~A}$ ).

In contrast, supernatants of measles-infected endothelial cells contained interferon beginning $24 \mathrm{~h}$ postinfection, which reached a maximum at $5 \mathrm{~d}$ (Fig. $8 \mathrm{~A}$ ). Interferon secreted by the measlesinfected cells was active on human, but not bovine fibroblasts, which suggest that endothelial cells secrete either $\beta$ - or $\gamma$-interferon (32). The addition of an anti- $\gamma$-interferon or an anti- $\alpha$ interferon antibody capable of neutralizing 20,000 $\mathrm{U}$ of interferon activity had no effect on the titer of interferon present in the supernatants of the measles-infected endothelial cells (Fig. $8 \mathrm{~B}$ ); furthermore, no $\gamma$-interferon was detectable by radioimmunoassay using a monoclonal anti- $\gamma$-interferon antibody (not 


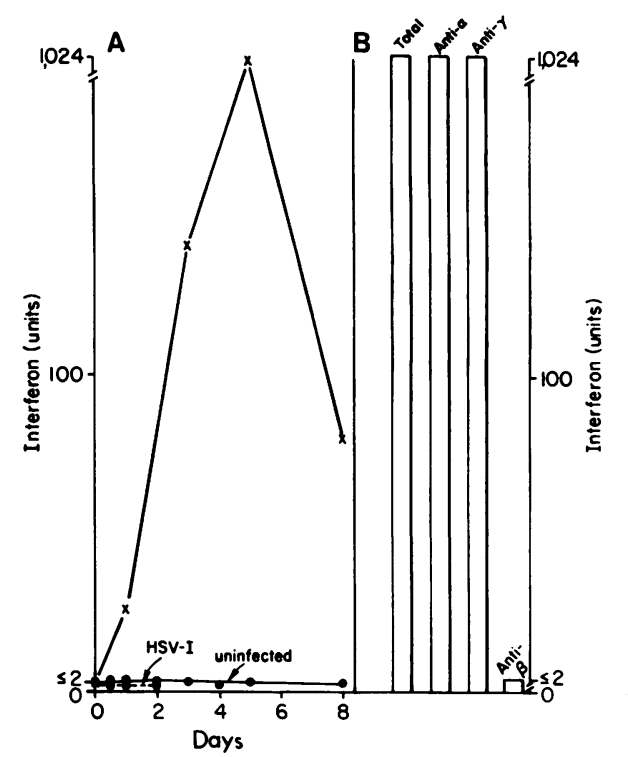

Figure 8. Production of interferon by endothelial cells. $(A)$ Supernatants from uninfected $(-\bullet-)$, HSV-I-infected $(\ldots \bullet \ldots)$, or measlesinfected $(-x-)$ passaged endothelial cells were assayed for interferon at various times after the onset of infection by their capacity to inhibit the cytopathic effect of vesicular stomatitis virus on human fibroblasts. $(B)$ Supernatants of the measles-infected cells $6 \mathrm{~d}$ after infection were incubated with antibodies specific for $\alpha$-, $\beta$-, or $\gamma$-interferon, and the residual interferon activity was determined.

shown). In contrast, addition of anti- $\beta$-interferon antibody totally eliminated detectable interferon activity in the endothelial cell supernatants (Fig. 8 B). Endothelial cells infected with UVinactivated HSV-I or measles did not secrete interferon. Therefore, it did not appear likely that the opposing effects of HSV-I and measles on the secretion of CSA by endothelial cells could be explained by the level of interferon secreted into the media. In addition, no interferon was detected in the MCM-stimulated cells, which indicates that its presence is not required to mediate CSA production by endothelial cells.

We next addressed the possibility that either $\alpha$ - or $\gamma$-interferon could immediately be taken up by surface receptors or could be acting within the cell and therefore be undetectable in the conditioned media. Endothelial cells incubated with 10 $1,000 \mathrm{U}$ of $\alpha$ - or $\gamma$-interferon secreted the same amount of CSA as control cultures (Fig. 9). The addition of $\alpha$ - or $\gamma$-interferon to endothelial cells incubated with MCM for $72 \mathrm{~h}$ caused a detectable reduction in the level of CSA produced by cells stim-

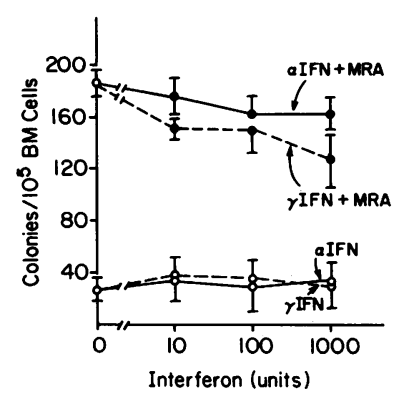

Figure 9. Effect of interferon on CSA production by endothelial cells. Passaged endothelial cells were incubated for $72 \mathrm{~h}$ in the presence of varying concentrations of $\alpha-(0-0)$ or $\gamma-(0-0)$ interferon and in the presence (top) or absence (bottom) of MCM (MRA). The culture supernatants were then harvested and assayed for CSA. The mean \pm SEM of eight experiments is shown. BM, bone marrow. ulated with MCM alone only at the highest interferon levels tested. Inhibition of CSA required amounts of interferon that would be $>100$-fold higher than those that could potentially be present in the supernatants of the virally infected endothelial cells and yet remain undetectable in our assay systems. In no case did the presence of interferon suppress the production of CSA to the levels seen after infection of endothelial cells with HSV-I (Figs. 8 and 9).

\section{Production of other inhibitors of CSA by endothelial cells}

We next sought to determine whether endothelial cells incubated with MCM or infected with either virus produced any inhibitor(s) of CSA activity in addition to interferon. To investigate whether such an inhibitor was present, we mixed conditioned medium, obtained between days 3 and 8, from uninfected or virally infected primary cultures or passaged endothelial cells, with PHALCM, a standard source of CSA, and the resultant number of CFC-GM was determined. Neither unstimulated, MCM-stimulated, nor HSV-I-infected endothelial cells produced any inhibitor that was biologically active in our assay system. Furthermore, no inhibitor was detected in supernatants of endothelial cell cultures infected with measles virus for up to $8 \mathrm{~d}$.

\section{Distribution of colony types induced by endothelial cell CSA}

We compared the distribution of colony cell types induced by CSA obtained from uninfected passaged endothelial cells stimulated with MCM (day 3) with the type of colonies induced by CSA prepared from PHA-stimulated lymphocytes (Fig. 10). Whereas PHA-LCM induced the formation of approximately equal numbers of granulocyte and macrophage colonies, endothelial cell CSA induced predominantly (75\%) granulocyte colonies. We observed this same predominance of granulocyte colonies when we studied endothelial cell CSA induced by measles infection (Fig. 10).

\section{Discussion}

Profound changes in hematopoiesis may accompany certain human viral infections. At the one extreme, aplastic anemia may follow an otherwise typical infection with hepatitis virus or in-

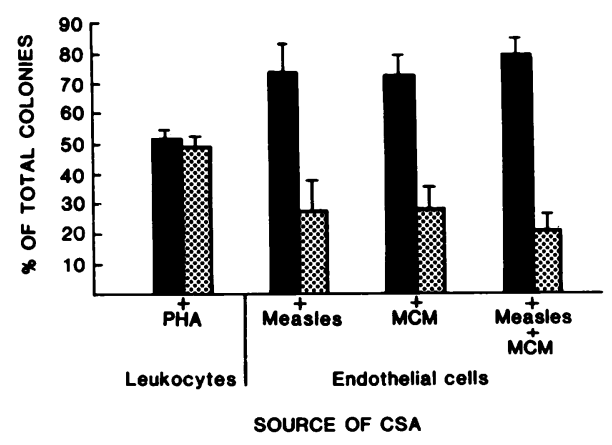

Figure 10. Types of colonies induced by endothelial cell-derived CSA. Conditioned media from PHA-stimulated leukocytes or endothelial cells stimulated by MCM, measles, or both were assayed for CSA. The type of colony cell that developed was determined using chloroacetate esterase to identify granulocytic ( $\square$ ) cells and NSE to identify monocytic ( $\square$ ) cells. The results are presented as a percent of the total colonies counted and represent the mean \pm SEM of four experiments. 
fluenza virus, or parvovirus $(10,11,19,36)$. A period of granulocytopenia frequently develops after infection with EBV or CMV (15-17). On the other hand, mild leukocytosis followed by mild leukpenia often follows both natural infection with measles virus and the administration of measles vaccine (37). Nevertheless, despite the frequent fluctuations of granulocyte counts that develop during viral infection, there has been little systematic study of the mechanisms by which this might occur.

Viral infection could effect hematopoiesis in a variety of ways. For example, parvovirus can infect and inhibit the development of erythroid colonies (BFU-E) in vitro, and clinical infection with the virus has recently been implicated in the development of aplastic crises in humans $(11,20)$. Similarly, infection of erythroid and myeloid precursors with hepatitis $B$ virus may play a role in the aplastic crises that occasionally follow such infections (38). Similar infection of bone marrow progenitor cells may occur after CMV infection (39). Granulocytopenia may also result from the induction of suppressor $T$ cells such as those that develop during EBV and CMV infection (15-18, 39, 40). Furthermore, a variety of cells produce $\alpha$-, $\beta$-, and $\gamma$-interferon after viral infection, and these molecules are known to have an inhibitory effect on myeloid (CFC-GM) colony formation in vitro $(9,41$, 42). Alternatively, several mechanisms have been described by which an expansion of the leukocyte pool may occur after viral infection. For example, infection of murine CFC-GM with the Friend virus complex leads to the loss of normal growth regulation by acidic isoferritin and lactoferrin (43). Furthermore, certain retroviruses have been shown to directly enhance the release of CSA by murine fibroblasts (20).

We therefore studied the possibility that viral infection of human endothelial cells might alter their production of CSA. Endothelial cells are a component of the normal bone marrow stroma (44) that can be readily infected by certain viruses in vitro and in vivo $(21,22)$ and have been shown by other investigators to produce CSA in culture $(29,45,46)$. There are conflicting data as to whether unstimulated endothelial cells produce significant amounts of CSA $(29,45)$. In agreement with Bagby et al. (29), we found that unstimulated passaged human endothelial cells derived from the umbilical vein produce little, if any, biologically active CSA. However, endothelial cells will produce CSA when stimulated by a low molecular weight heatlabile glycoprotein produced and secreted by normal monocytes, which has been called MRA and which is found in MCM (29). We have shown that the induction of CSA release from endothelial cells requires the continued presence of MCM (Fig. 3) and active protein synthesis by the endothelial cell, and that little additional CSA remains stored within the endothelial cell cytosol (Fig. 3). It is possible that the presence of CSA found in the supernatants of primary cultures of endothelial cells reflects stimulation in vivo by products of monocytes present in the fetal circulation.

The production of CSA by endothelial cells was also altered by certain viral infections. Infection with HSV-I totally prevented the production of CSA by endothelial cells stimulated by MCM. Total inhibition occurred within $4 \mathrm{~h}$ of infection, before the appearance of cytopathic changes, cell lysis, or production of intact virus particles (22). This inhibition of CSA synthesis occurs at a time when HSV-I is known to inhibit the synthesis of many host proteins $(47,48)$. We investigated the possibility that live herpes virus was present in supernatants of some of these cultures. Such residual virus could have infected the hematopoeitic stem cells and directly inhibited colony growth in vitro. However,
CSA production remained undetectable even after any potential live virus was removed from the Endo-CM by UV inactivation and ultracentrifugation. Furthermore, we found no functional inhibitor of CFC-GM colony formation when these supernatants were mixed with a known amount of CSA and added to the human marrow cell culture. This finding argues against any effect of residual live virus on the measurements of CSA we made. Therefore, it is more likely that herpes simplex directly inhibits the ability of MCM to induce CSA production by endothelial cells. This could be brought about in two ways. Firstly, the lack of CSA production could be part of the general effect of HSV-I to inhibit synthesis of certain cell-specific proteins $(47,48)$. Secondly, the failure to respond to MCM could reflect loss of a receptor for MRA or a specific inhibition by the virus of an intracellular event necessary for CSA production or secretion.

In contrast to the results of infection with HSV-I, endothelial cells infected with measles virus were stimulated to produce CSA for the first 24-72 $\mathrm{h}$ after infection in the absence of MCM. Furthermore, measles-infected cells remained responsive to MCM for $6 \mathrm{~d}$ in culture, well after measles-induced syncytia begin to form (22). The mechanism by which measles virus stimulates endothelial cells to produce CSA is unknown. The measurement of CSA in the supernatants of the measles-infected endothelial cells was not due to the presence of live virus capable of directly infecting the bone marrow target cells. After UV inactivation and ultracentrifugation of the Endo-CM, no live measles virus was detected in a permissive cell line, although the level of CSA in the Endo-CM was unaffected. Nor was the presence of CSA in the supernatants of measles-infected endothelial cells due to a toxic or lytic effect of the virus on the cells. Endothelial cells appear to store little functionally active CSA, at least free within the cytosol. Active protein synthesis is required for the appearance of CSA in the culture medium, and infection with HSV-I, which is capable of lysing endothelial cells, produces the opposite effect. Therefore, the appearance of CSA after measles infection probably involves stimulation of the synthesis of this glycoprotein within the infected endothelial cells.

In all of our studies, we used nonadherent human bone marrow cells as targets to determine the amount of CSA in our endothelial cell supernatants. This nonadherent cell fraction is heterogeneous and includes various potential accessory cell populations, such as lymphocytes and fibroblasts, in addition to hematopoietic stem cells. Therefore, the conditioned medium secreted by the MRA-stimulated or the measles-infected endothelial cells could contain factors that promote CFC-GM development indirectly, through one or more of these accessory cell populations (31). Assays using purified human bone marrow stem cells would be required to determine unequivocally the production of CSA itself by endothelial cells.

We studied the role of interferon in the production of CSA that we observed. We first asked if the failure of HSV-I-infected endothelial cells to produce CSA, even following stimulation with MCM, could be due to the presence of $\alpha$-, $\beta$-, or $\gamma$-interferon in these cell supernatants, since it is known that these molecules can inhibit the development of CFC-GM in the marrow system we employed $(9,41,42)$. However, we found that $\beta$-interferon was produced during measles virus but not HSV-I infection of endothelial cells. Indeed, the supernatants of endothelial cells infected with measles virus contained both $\beta$-interferon as well as functioning CSA. Therefore, based on the known inhibitory effects of interferon on hematopoiesis, the opposite effects of these two viruses on CSA production by endothelial cells cannot 
be explained solely by their effect on the amount or type of interferon they induce endothelial cells to secrete.

We then considered the possibility that the production of CSA by measles-infected or MCM-stimulated endothelial cells could be mediated, in part, by the synthesis of an interferon molecule having MRA-like activity. Recently (49), endothelial cells have been reported to produce small amounts of CSA-like activity after incubation with gamma interferon, although the number of colonies that could be induced to develop could not account for the magnitude of the results we observed. However, we did not detect $\gamma$-interferon in the supernatants of the MCMstimulated or measles-infected endothelial cells. It is possible that these cultures might have contained small amounts of $\alpha$ or $\gamma$-interferon, which were below our ability to detect, or which immediately bound to endothelial cell receptors, or which acted within the cells to cause CSA production. However, we found that the addition of relatively small or relatively large amounts of $\alpha$ - or $\gamma$-interferon to endothelial cell cultures, in the absence of MCM, did not initiate production of CSA, excluding a direct MRA-like activity for these molecules, at least under the experimental conditions and using the assay system we employed.

We did not directly study the effect of purified $\beta$-interferon, a known inhibitor of CFC-GM development, on the production of CSA by endothelial cells. Therefore, we cannot exclude the possibility that $\beta$-interferon plays a role in the production of CSA by measles-infected endothelial cells or the possibility that a lack of $\beta$-interferon production by HSV-I-infected cells accounts for the absence of CSA production induced by this virus. We also did not study the effect on CSA production of adding either interferon or anti-interferon antibodies to virally infected endothelial cells. Therefore, our experiments also do not exclude the possibility that interferon participates in the overall regulation of CSA production under some circumstances. Certainly, the secretion of interferon by virally infected stromal cells would be expected to effect the response of the bone marrow target cells to CSA and other regulatory molecules. Moreover, interferon may only stimulate endothelial cells to produce CSA after the addition of other biologically active molecules (50). However, the absence of significant amounts of interferon in the supernatants of MCM-stimulated cells does suggest that secretion of interferon into the Endo-CM is not required for CSA production, at least when stimulated in this way.

It is also far from certain whether the changes in granulocyte count that occur during viral infection in vivo actually result from the type of changes in the levels of CSA we observed in this study. Viral infections could either alter monocyte production of MRA, change the levels of prostaglandin $E_{2}$, acidic isoferritins, lactoferrin, or local concentrations of interferon within the marrow, or lead to the production of inhibitors of MRA itself. Furthermore, certain viruses may directly alter the responsiveness of bone marrow cells at various stages of differentiation to these regulatory signals. However, it is also possible that transient or persistent changes in CSA production by endothelial cells or other components of the bone marrow stroma may, in fact, play a role in certain clinically important disorders of myelopoiesis.

\section{Acknowledgments}

We thank Rena Finko and Jeffrey Hastings for their expert technical assistance and Mrs. Patricia Lafferty, Diane Tate, and Diane Meredith for preparation of the manuscript. We thank Drs. Bice Perussia and Giorgio Trinchieri of the Wistar Institute, Philadelphia, PA, for the gifts of $\alpha$ - and $\gamma$-interferon and for performance of the interferon assays. We thank the nursing staffs of the Obstetrical Departments of Delaware County Memorial Hospital and Pennsylvania Hospital for their help in obtaining the umbilical cords used in this study.

This work was supported in part by grants ES-00134, HL28220, and HL34044 from the National Institutes of Health, grant 1646 to Dr. Cines from the Council for Tobacco Research, and a grant from the Sohio Foundation to Dr. Gerson. Dr. Cines is the recipient of a research career development award (1-K04-HL00956) from the National Institutes of Health.

\section{References}

1. Burgess, A. W., and D. Metcalf. 1980 . The nature and action of granulocyte-macrophage colony stimulating factors. Blood. 56:947-958.

2. Kimura, N., Y. Niho, and T. Yanase. 1982. A high level of colony stimulating activity in a lung cancer patient with extensive leukocytosis and the establishment of CSA producing cell line (KONT). Scand. J. Haematol. 28:417-424.

3. Verma, D. S., G. Spitzer, A. R. Zander, R. Fisher, K. B. McCredie, and K. A. Dicke. 1979. T lymphocyte and monocyte-macrophage interaction in colony-stimulating activity elaboration in man. Blood. 54: 1376-1383.

4. Iscove, N. N., C. A. Roisch, N. Williams, and L. J. Guilbert. 1982. Molecules stimulating early red cell, granulocyte, macrophage and megakaryocyte precursors in culture: similarity in size, hydrophobicity and charge. J. Cell. Physiol. 1(Suppl. 1):65-78.

5. Metcalf, D., G. R. Johnson, and A. W. Burgess. 1980. Direct stimulation by purified GM-CSF on the proliferation of multipotential and erythroid precursor cells. Blood. 55:138-147.

6. Pelus, L. M., H. E. Broxmeyer, J. I. Kurland, M. A. S. Moore. 1979. Regulation of macrophage and granulocyte proliferation. J. Exp. Med. 250:277-292.

7. Bagby, G. C., V. D. Rigas, R. M. Bennett, A. A. Vandenbark, and H. S. Garwal. 1981. Interaction of lactoferrin, monocytes and T lymphocyte subsets in the regulation of steady state granulopoiesis in vitro. J. Clin. Invest. 68:56-77.

8. Broxmeyer, H. E., J. Bognacki, P. Ralph, R. P. Dorner, L. Lu, and $\mathrm{H}$. Castro-Malaspina. 1982. Monocyte-macrophage-derived acidic isoferritins: normal feedback regulators of granulocyte-macrophage progenitor cells in vitro. Blood. 60:595-607.

9. Klimpel, G. R., W. R. Fleischmann, Jr., and K. D. Klimpel. 1982. Gamma interferon (IFN $\gamma$ ) and IFN $\alpha / \beta$ suppress murine myeloid colony formation (CFU-C): magnitude of suppression is dependent upon level of colony-stimulating factor (CSF). J. Immunol. 129:76-80.

10. Curzon, P. G. D., M. F. Muers, and S. M. Rajah. 1983. Aplastic anemia associated with influenza A infection. Scand. J. Haematol. 30: 232-234.

11. Davis, L. R. 1983. Aplastic crises in haemolytic anemias: the role of parvovirus-like agent. Br. J. Haematol. 55:391-393.

12. Carter, R. L. 1966. Granulocyte changes in infectious mononucleosis. J. Clin. Pathol. (Lond.). 19:279-283.

13. Robinson, W. A., M. A. Entringer, R. W. Bolin, and A. Mangalik. 1978. WBC and micro-organism interaction in granulocyte regulation. In Hematopoietic Cell Differentiation. Academic Press, Inc., New York. 471-478.

14. Schrader, J. W., and I. Clark-Lewis. 1982. T cell derived factor stimulating multipotential hemopoietic stem cells: molecular weight and distinction from $\mathrm{T}$ cell growth factor and $\mathrm{T}$ cell derived granulocytemacrophage colony stimulating factor. J. Immunol. 129:30-50.

15. Schooley, R. T., B. F. Haynes, J. Grouse, C. Payling-Wright, A. S. Fauci, and R. Dolin. 1981. Development of suppressor T lymphocytes for Epstein-Barr virus-induced B-lymphocyte outgrowth during acute infectious mononucleosis: assessment of two quantitative systems. Blood. 57:510-517. 
16. Moss, D. J., A. B. Rickinson, and J. H. Pope. 1982. Long-term T-cell-mediated immunity to Epstein-Barr virus in man. III. Activation of cytotoxic T cells in virus-infected leukocyte cultures. Int. J. Cancer. 23:618-625.

17. Schooley, R. T., M. S. Hirsch, R. B. Colvin, B. Cosimi, N. E. Tolkoff-Rubin, R. T. McCluskey, R. C. Burton, P. S. Russell, J. T. Herrin, F. L. Delmonico, J. V. Giongi, W. Henle, and R. H. Rubin. 1973. Association of herpes virus infections with T-lymphocyte subset alterations, glomerulopathy, and opportunistic infections after renal transplantation. N. Engl. J. Med. 308:307-311.

18. Podesta, M., F. Frassoni, M. T. van Lint, G. Piaggio, G. Marmont, and A. Bacigalupo. 1982. Generation of CFU-C suppressor T cells in vitro. II. Effect of PHA, PWM, and Con A on bone marrow and peripheral blood lymphocytes from healthy donors. Exp. Hematol. (Lawrence). 9: 473-478.

19. Young, N. S., P. P. Mortima, J. G. Moore, and R. K. Humphrey. 1984. Characterization of a virus that causes transient aplastic anemia. J. Clin. Invest. 73:224-231.

20. Koury, M. J., and I. B. Pragnell. 1982. Retroviruses induce granulocyte-macrophage colony stimulating activity in fibroblasts. Nature (Lond.). 299:638-640.

21. MacGregor, R. R., H. M. Friedman, E. J. Macarak, and N. A. Kelfalides. 1980. Virus infection of endothelial cells increases granulocyte adherence. J. Clin. Invest. 65:1469-1477.

22. Friedman, H. M., E. J. Macarak, R. R. MacGregor, J. Wolfe, and N. A. Kefalides. 1981. Virus infection of endothelial cells. J. Infect. Dis. 143:266-273.

23. Cines, D. B., A. P. Lyss, M. Bina, R. Corkey, N. A. Kelfalides, and $H$. M. Friedman. 1982. Herpes simplex virus enhances the expression of receptors for $\mathrm{C} 3$ and the $\mathrm{Fc}$ portion of immunoglobulin $\mathrm{G}$ on human endothelial cells. J. Clin. Invest. 69:123-128.

24. Jaffe, E. A., R. A. Nachman, C. G. Becker, and C. R. Minick. 1973. Culture of human endothelial cells derived from umbilical veins. Identification by morphologic and immunologic criteria. J. Clin. Invest. 52:2745-2756.

25. Gimbrone, M. A., R. S. Cotran, and J. Folkman. 1974. Human vascular endothelial cells in culture. J. Cell Biol. 60:673-684.

26. Cines, D. B., A. P. Lyss, M. Reeber, M. Bina, and R. J. DeHoratious. 1984. Presence of complement-fixing anti-endothelial cell antibodies in systemic lupus erythematosus. J. Clin. Invest. 73:611-625.

27. Maciag, T., J. Cerundolo, S. Ilsley, P. R. Kelley, and R. Forand. 1979. An endothelial cell growth factor from bovine hypothalamus: identification and partial characterization. Proc. Natl. Acad. Sci. USA. 76:5674-5678.

28. Booyse, F. M., A. J. Quarfoot, J. Chediak, M. B. Stemerman, and T. Maciag. 1981. Characterization and properties of cultured human umbilical vein endothelial cells. Blood. 58:788-796.

29. Bagby, G. C., Jr., E. McCall, K. A. Bergstrom, and D. Burger. 1983. A monokine regulates colony-stimulating activity production by vascular endothelial cells. Blood. 62:663-668.

30. Bagby, G. C., E. McCall, and D. L. Layman. 1983. Regulation of colony-stimulating activity production. Interaction of fibroblasts, mononuclear phagocytes and lactoferrin. J. Clin. Invest. 71:340-344.

31. Gerson, S. L., and R. A. Cooper. 1984. Release of granulocytespecific colony-stimulating activity by human bone marrow exposed to phorbol esters. Blood. 63:878-885.

32. Perussia, B., E. T. Dayton, R. Lazarus, V. Fanning, and G. Trinchieri. 1983. Immune interferon induces the receptor for monomeric IgGl on human monocytic and myeloid cells. J. Exp. Med. 158:10921113.
33. Trinchieri, G., M. Matsumoto-Kobayashi, S. C. Clark, J. Sechra, L. London, and B. Perussia. 1984. Response of resting human peripheral blood natural killer cells to interleukin 2. J. Exp. Med. 160:1147-1169.

34. Abrahm, J. L., and R. Smiley. 1981. Modification of normal human myelopoiesis by 12-O-tetradecanolyphorbol-13-acetate (TPA). Blood. 58:1119-1126.

35. Pober, J. S., M. A. Gimbrone, Jr., R. S. Cotran, C. S. Reiss, S. J. Burakoff, W. Fiers, and K. A. Ault. 1983. Ia expression by vascular endothelium is inducible by activated $T$ cells and by human gamma interferon. J. Exp. Med. 157:1339-1353.

36. Hagler, L., R. A. Pastore, and J. J. Bergin. 1975. Aplastic anemia following viral hepatitis: report of two fatal cases and literature review. Medicine (Baltimore). 54:139-164.

37. Black, F. L., and S. R. Sheridan. 1967. Blood leukocyte response to live measles virus. Am. J. Dis. Child. 113:301-308.

38. Mugishima, H. B., J. B. Zeldis, E. Nir, and R. P. Gale. 1984. Hepatitis B-virus inhibition of myeloid stem cells. Blood. 64(Suppl.): 107a. (Abstr.)

39. Petrusson, S. R., P. A. Chervenick, and G. Wu. 1984. Megakaryocytopoesis and granulopoesis after murine cytomegalovirus infection. J. Lab. Clin. Med. 104:381-390.

40. Bagby, G. C., Jr., H. J. Lawrence, and R. C. Neerhout. 1983. Tlymphocyte-mediated granulopoietic failure. In vitro identification of prednisone-responsive patients. N. Engl. J. Med. 309:1073-1078.

41. Newman, H. A., and A. A. Fauser. 1982. Effect of interferon on pluripotent hemopoietic progenitors (CFU-GEMM) derived from human bone marrow. Exp. Hematol. (Lawrence). 10:587-596.

42. Broxmeyer, H. E., L. Lu, E. Platzer, C. Feit, L. Juliano, and B. Y. Rubin. 1983. Comparative analysis of the influences of human gamma, alpha and beta interferons on human multipotential (CFUGEMM), erythroid (BFU-E) and granulocyte-macrophage (CFU-GM) progenitor cells. J. Immunol. 131:1300-1305.

43. Lu, L., H. E. Broxmeyer, M. A. S. Moore, A. P. Sheridan, and P. Gentile. 1985. Abnormalities in myelopoietic regulatory interactions with acidic isoferritins and lactoferrin in mice infected with the Friend virus complex: association with altered expression of Ia antigens on effector and responding cells. Blood. 65:91-99.

44. Dexter, T. M., E. Sponcer, D. Toksoz, and L. G. Lajtha. 1980. The role of cells and their products in the regulation of in vitro stem cell proliferation and granulocyte development. J. Supramol. Struct. 13:513524.

45. Quesenberry, P. J., and M. A. Gimbrone. 1980. Vascular endothelium as a regulator of granulopoiesis: production of colony-stimulating activity by cultured human endothelial cells. Blood. 56:10601067.

46. Ascensao, J. L., G. M. Vercellotti, H. S. Jacob, and E. D. Zanjani. 1984. Role of endothelial cells in human hematopoesis: modulation of mixed colony growth in vitro. Blood. 63:553-558.

47. Fenwick, M. L., and M. J. Walker. 1978. Suppression of the synthesis of cellular macromolecules by herpes simplex virus. J. Gen. Virol. 41:37-51.

48. Fenwick, M. L., and J. Clark. 1982. Early and delayed shut off of host protein synthesis in cells infected with herpes simplex virus. $J$. Gen. Virol. 61:121-125.

49. Ascensao, J. L., and G. M. Vercelotti. 1985. Endothelial cell production of hemopoietic growth factors: modulation by recombinant human gamma interferon. Clin. Res. 33:334a. (Abstr.)

50. Montesano, R., L. Orci, and P. Vassalli. 1985. Human endothelial cell cultures: phenotypic modulation by leukocyte interleukins. J. Cell. Physiol. 122:424-434. 